\title{
COMPARISON OF FIB TEM SPECIMEN PREPARATION METHODS
}

\author{
Ron Anderson
}

Microscopy Today*

The increasingly wide-spread adoption of the focused ion beam (FIB) method for making TEM specimens in the semiconductor industry and elsewhere has spawned several competing methodologies. This paper compares the pros and cons of the various methods used today in a table. Important points are italicized.

In the first column we see the original method proposed to make TEM specimens, [1] which some researchers call the "H-bar" method because a SEM view of the finished sample looks like the capitol letter "H." Briefly, the sample is located, rough cut from its matrix, and polished to a thickness of about 50 to 100 microns. The specimen is mounted on a half-grid (a large, single-hole, aperture grid with one side cut away to allow the FIB beam to strike the edge of the specimen). In the FIB, the location of the finished TEM specimen is coated with a W or Pt line and large trenches are cut on either side of the desired location using large apertures. Final cuts are made to thin and clean the resulting specimen. Because of the TEM tilt limitations and the probability of the specimen suffering severe FIB artifact contamination, this method has little to recommend it in the face of newer protocols.

The combined tripod and " $\mathrm{H}$ " pattern method is actually a trivial modification of the conventional "H" pattern method [2]. The difference between the two protocols is that the specimen is initially polished to a thickness less than 10 microns instead of 50 to 100 microns. The end result of making the specimen thinner before FIBing, besides shorter FIB times, is that the resulting specimen geometry allows the specimen to be ion milled after thinning from the substrate side. The benefits of ion milling the FIBed specimen are substantial. First, the resulting specimen can be tilted to the full range of the TEM instrument's tilt capability. Second, the specimen is made thinner, frequently making HRTEM imaging of atom columns in the specimen possible. Third, the thick (20 nm or so) amorphous layer created by the 30 to $50 \mathrm{keV}$ FIB beam can be replaced by the negligible, order-ofmagnitude thinner amorphous layer created by argon ion milling at 2 or $3 \mathrm{keV}$ at near grazing incidence. And lastly, any FIB back sputtered artifactual material on the specimen can be removed. Both " $\mathrm{H}$ " pattern methods have the disadvantage of requiring a mechanical polishing step but the times to make specimens compare well with the lift-out methods.

The lift-out methods [3] are well covered in considerable detail in the recent literature. Ex-situ removal is when the specimen is plucked from the substrate outside the FIB tool via electrostatic pick-up on a glass filament and then placed on a carbon-film coated TEM grid. In-situ mounting is accomplished in the FIB tool via fastening the specimen to a transfer fixture, plucking it from the substrate, and then fastening it to a TEM grid all inside the FIB. The lift-out, ex-situ grid mounting method is very fast, produces specimens that do not limit the TEM tilt capability, and automation of the initial preparation steps is possible. The main disadvantage is that no further thinning or artifact 


\begin{tabular}{|c|c|c|c|c|}
\hline & $\begin{array}{c}\text { Conventional "H" } \\
\text { Pattern }\end{array}$ & $\begin{array}{l}\text { Combined Tripod } \\
\text { and "H" Pattern }\end{array}$ & $\begin{array}{l}\text { Lift-Out Method } \\
\text { External Grid } \\
\text { Mounting }\end{array}$ & $\begin{array}{l}\text { Lift-Out Method } \\
\text { Internal Grid } \\
\text { Mounting }\end{array}$ \\
\hline Pros & $\begin{array}{l}\text { Can put back into } \\
\text { FIB for additional } \\
\text { thinning } \\
\text { Multiple specimen } \\
\text { sites per initial prep }\end{array}$ & $\begin{array}{l}\text { Can put back } \\
\text { into FIB for } \\
\text { additional } \\
\text { thinning } \\
\text { Can be ion } \\
\text { milled to make } \\
\text { thinner and to } \\
\text { remove FIB } \\
\text { artifacts } \\
\text { Full TEM tilt } \\
\text { capability } \\
\text { Multiple } \\
\text { specimen sites } \\
\text { per initial } \\
\text { prep }\end{array}$ & 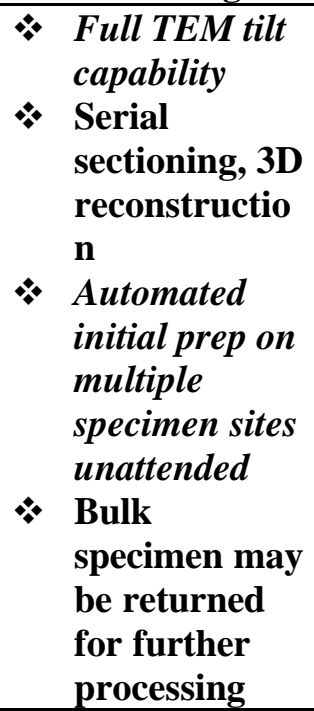 & $\begin{array}{l}\text { As for Lift-Out } \\
\text { external } \\
\text { mounting } \\
\text { Ion milling } \\
\text { possible for } \\
\text { additional } \\
\text { thinning and } \\
\text { artifact } \\
\text { reduction }\end{array}$ \\
\hline Cons & $\begin{array}{l}\text { Destructive to bulk } \\
\text { specimen }\end{array}$ & $\begin{array}{l}\text { Destructive to } \\
\text { bulk specimen }\end{array}$ & $\begin{array}{ll}* & \text { No additional } \\
\text { FIB or ion } \\
\text { milling } \\
\text { possible } \\
\text { FIB Artifacts } \\
\text { Inapplicable } \\
\text { for fragile } \\
\text { specimens } \\
\end{array}$ & $\begin{array}{l}\text { Additional ion } \\
\text { milling may } \\
\text { be one-sided } \\
\text { only } \\
\text { Possible ion } \\
\text { mill artifacts }\end{array}$ \\
\hline Speed & $\begin{array}{l}1 \text { to } 4 \text { Hours } \\
\text { depending on target } \\
\text { size }\end{array}$ & $\begin{array}{l}1 \text { to } 4 \text { Hours } \\
\text { depending on } \\
\text { target size }\end{array}$ & $\begin{array}{l}1 \text { to } 2 \text { Hours } \\
\text { depending on } \\
\text { target size }\end{array}$ & $\begin{array}{l}1 \text { to } 4 \text { Hours } \\
\text { depending on } \\
\text { target size }\end{array}$ \\
\hline
\end{tabular}

removal is possible on the specimen sliver resting on the thin carbon film. Whatever you get is all there is. If you aren't happy with the TEM specimen you must start over again. The in-situ method is newly developed and very promising. It combines all of the advantages of the ex-situ method but offers the possibility of subsequently ion milling the resulting specimen to further thin the specimen and to remove artifacts. The times cited are for experienced operators and include all pre- and postFIB-tool specimen site selection, cutting or polishing as appropriate, and mounting the resulting specimen. All the methods are capable of high target specificity, it just takes longer to prepare very small pre-specified locations. Likewise, very hard materials, like jet engine turbine blades, take far longer to process in every phase compared to silicon specimens.

References

[1] Kirk EC et al. (1989) Inst. Phys. Conf. Series, 100, p 501

[2] Klepeis SJ (1998), Proc. of the $14^{\text {th }}$ Int. Cong. on Electron Microscopy, Cancun, Mexico.

[3] Overwijk MHF et al. (1993) J. Vac. Sci. Technol. B 11(6), pp. 2021-2024.

*Formerly IBM East Fishkill (retired) presently Editor-in-Chief of Microscopy Today magazine 